\title{
DESIGN OF SMALL UNMANNED VEHICLE INTELLIGENT TRANSMISSION SYSTEM BASED ON PID CONTROL ALGORITHM
}

\author{
Xiangwei Li \\ School of Mechatronics, Guangdong Industry Polytechnic, Guangzhou, 510300, China \\ E-mail: fengzhizi12345@126.com
}

\begin{abstract}
As the future development direction of automobiles, unmanned driving has received wide attention from all walks of life. Unmanned shifting technology plays an important role in the overall performance of driverless driving.The small unmanned vehicle intelligent shifting system based on PID control algorithm is designed in this paper. After the environmental information around the vehicle is collected by the laser radar high-speed data acquisition module, it is transmitted to the decision-making planning module.According to the detailed information, the corresponding operation instructions are given to the driverless smart car. Operational commands are transmitted to the motor drive module to control intelligent shifting. Therefore, the vehicle dynamics model is constructed, and the speed control strategy based on the improved PID control algorithm is used to complete the intelligent shift control of the unmanned vehicle. The experimental results show that the system can effectively control the intelligent shifting of the unmanned vehicle under different scene settings, and the control effect is ideal, as well as it has good control efficiency and can meet the requirements of the variable speed control of the unmanned vehicle.
\end{abstract}

Keywords: PID Control; Unmanned Vehicle; Intelligent Shifting; Lidar; Decision Making; Motor Drive.

\section{Introduction}

Unmanned driving as the future research direction for automobiles has the profound impact on the automotive industry and even the transportation industry (Song et al. 2017).

The advent of driverless cars will liberate human hands, reduce the frequency of traffic accidents and ensure people's safety (Luoet al. 2018).With the breakthrough and advancement of core technologies such as artificial intelligence and sensor detection, unmanned driving will be more intelligent, and unmanned vehicles can also be industrialized (Rahman et al. 2016).But the emergence of any technology is a process of gradual and continuous innovation. Unmanned driving from emergence to maturity, and worldwide use, requires the unremitting efforts of every car owner (Xing et al. 2016). As the first company to develop unmanned technology, Google Inc. has developed the fullyautomated driving vehicle that can automatically start and stop. The Google Autopilot project is reorganized into the independent company called Waymo. Waymo announced on November 7, 2017 that it will test unmanned cars without safety drivers (Ali 2017).Driverless car testing activities will accelerate in 2018. In 2018, Waymo will deploy more fully driverless cars on the road. In addition to the traditional automotive industry and Internet companies such as Google have begun research and development of driverless cars and have achieved very good results, Apple, Uber, etc. have also tilted the scope of business to driverless cars (Wang et al. 2017). At present, domestic Baidu, Chang'an and other enterprises as well as the National Defense University of Science and Technology, the military transportation college's driverless cars are at the forefront of domestic research and development. For example, Chang'an Automobile realized that the driverless car departed from Chongqing all the way north to Beijing and broke the long-distance driving record of the domestic driverless car (Hasanien 2018).Baidu also carried out the first experiment of the driverless car in Beijing and achieved success. By 2020, unmanned vehicles are expected to achieve road testing (Hasanien 2018) on the Yanchong Expressway from Beijing to Chongli. The rapid development of related technologies has undoubtedly provided strong technical support for the future of unmanned driving (Ren et al. 2016).

During the driving process, the driving conditions are constantly changing. A large number of unknown and non-linear factors in the power transmission system bring different degrees of difficulty to the system control of the driverless vehicle, especially the transition process such as shifting and braking.

During the operation of the drive motor, its three performance indexes of speed, torque and power 
will change with the change of load (Chenet al. 2017). Matching the motor to the transmission, the gear ratio of the reducer and the number of gears in the transmission system can achieve good vehicle dynamics and economy (Gao et al. 2018). Therefore, when the driverless car is modified on the basis of the new energy vehicle, if the motor or the transmission is modified separately, the original output characteristic curve will be destroyed without considering the inherent dynamic characteristics of the vehicle itself. This will cause a series of problems such as vehicle dynamics, economy and poor transition quality (Wei et al. 2017). This paper designs the small unmanned vehicle intelligent shifting system based on PID control algorithm, and applies the PID control algorithm to the small unmanned vehicle intelligent shifting system to meet the requirements of the unmanned vehicle shift control (Brocket al. 2016).

\section{Materials and Methods}

\subsection{System hardware design}

In the small unmanned vehicle intelligent shifting system based on the PID control algorithm, the lidar high-speed data acquisition module collects the environmental information around the vehicle and transmits it to the decision planning module.

Based on the detailed information, the decision planning module makes corresponding operational instructions for the driverless smart car. It is then transmitted to the motor drive module for intelligent shift control (Lv\&Liu 2016).

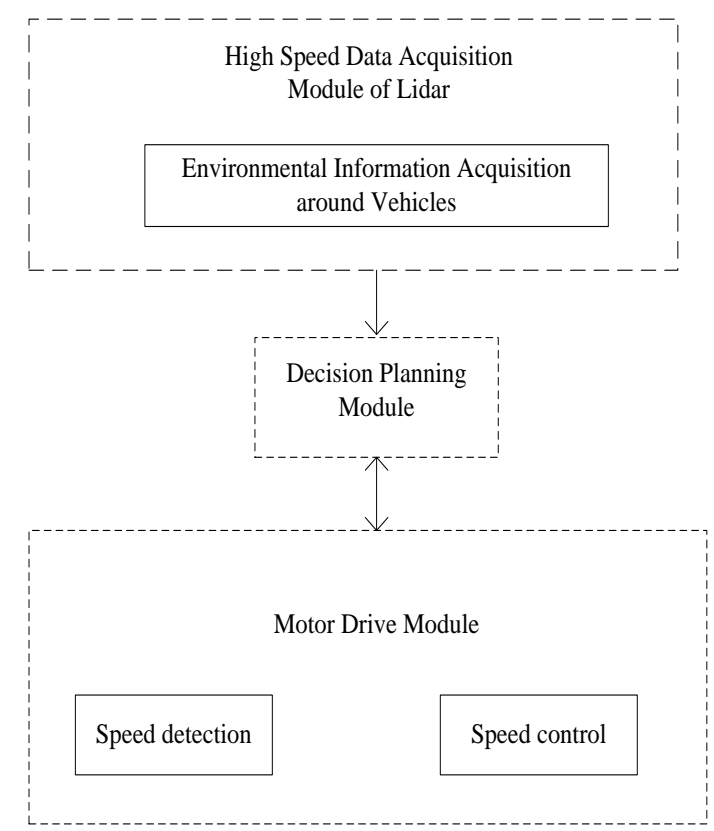

Figure 1: Intelligent Transmission System for Small Unmanned Vehicle Based on PID Control Algorithms
(1) Lidar high-speed data acquisition module

The vehicle laser radar senses the environmental information around the vehicle. The data acquisition control module uses FPGA and DSP as the core components. The overall structure of the lidar data acquisition module of the unmanned vehicle is shown in Fig. 2:

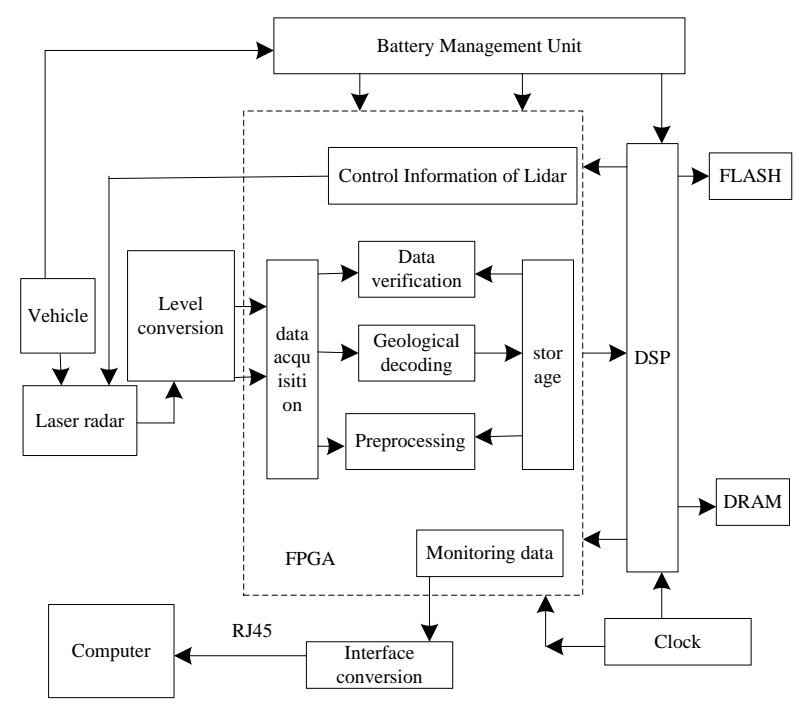

Figure 2: The overall structure of high-speed data acquisition module for lidar

In the high-speed data acquisition module of Lidar, the 4-channel on-board lidar data is connected to the FPGA through the level matching circuit. The FPGA selects Xilinx's XC3S400, which uses 90nm technology, has a maximum capacity of 400,000 gates, and comes with 16 block RAMs. Its operating frequency can reach $200 \mathrm{MHz}$, which is the core device of data acquisition. The FPGA collects 4 channels of lidar data in parallel at a rate of $500 \mathrm{~K}$ baud, generates an address decoding signal at the same time, and stores the data in the block RAM of the FPGA under the action of the address decoding signal.

(2) Decision planning module

The decision-making module integrates the environment and vehicle information to enable unmanned vehicles to generate safe and reasonable driving behavior and to guide the motion control system to control the vehicle (Jin \& Han 2017).

The behavior decision sub-module is a narrow decision-making module that makes a reasonable decision on the behavior of the current vehicle based on the information output by the lidar high-speed data acquisition module, and determines the constraints of the trajectory planning according to different behaviors. It is used to guide the trajectory planning module to plan for appropriate path, vehicle speed, etc., and send it to the underlying control module for variable speed control (Du et al. 2016). 
Fig. 3 shows the structure of the decision planning module:

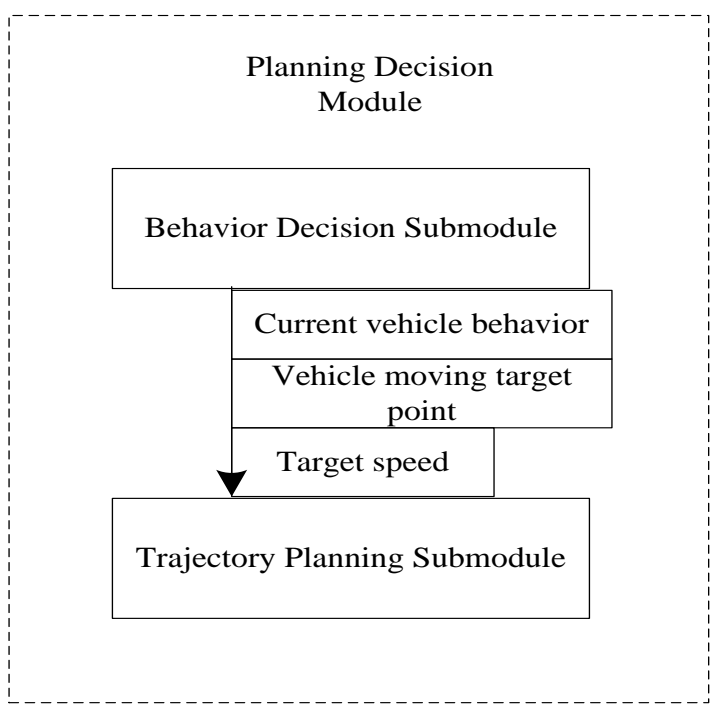

Figure 3: Structural diagram of planning and decision module

(3) Motor drive module

The motor is a DC motor of the RS-380 model, and its rated working voltage is $7.2 \mathrm{~V}$, which can output $0.9-40 \mathrm{~W}$ power. Two MC22886 chips are connected in parallel to drive the motor, and the MC33886 is the H-bridge power switch IC.

Combined with internal control logic, charge pump, gate driver, and MOSFET output circuitry, the IC can operate from 5 to 40 volts. The output is adjusted by the PWM signal to adjust the motor speed. The PWM control frequency is $1 \mathrm{KHz}, \mathrm{PWM} 23$ can be used for forward rotation control, PWM45 can be used for reverse control, OUT1 and OUT2 are connected to DC motor for fast acceleration in straight track and reverse braking of curve (Fillafer \& Schneider 2016).

Motor drive module structure shown in Fig. 4:

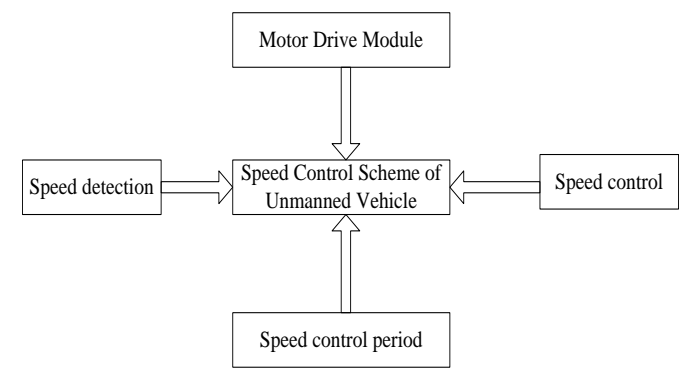

Figure 4: Structure diagram of motor driving die

\subsection{System software design}

\subsubsection{Construction of vehicle dynamics model}

\section{(1) Vehicle dynamics model}

According to the matching experimental vehicle parameters, the corresponding vehicle numerical simulation model is established, and the influence of actual air resistance, rolling resistance, suspension system and steering system is ignored. Considering the main influencing factors affecting the car's shifting, a nine-degree-of-freedom vehicle model that better reflects the dynamic characteristics of the actual test vehicle is established (Yuet al. 2016).

Specifically, it includes the longitudinal movement of the car along the $\mathrm{X}$ axis, the lateral movement along the $Y$ axis, the roll motion about the $\mathrm{X}$ axis, the yaw motion about the $\mathrm{Z}$ axis, and the rotational motion of the four wheels about their respective axes and the change of the front wheel angle (Xie \& Lynch 2016).

The longitudinal motion equation of the car:

$$
m\left(\dot{v}_{x}-v_{y} w_{r}\right)+m e w_{r} \dot{\varphi}=\sum F_{x}
$$

The lateral motion equation of the car:

$$
m\left(\dot{v}_{y}-v_{x} w_{r}\right)+m e w_{r} \ddot{\varphi}=\sum F_{y}
$$

The yaw motion equation of a car:

$$
I_{z} \dot{w}_{r}+I_{x z} \ddot{\varphi}=\sum M_{z}+\Delta M
$$

The roll motion equation of the car:

$$
I_{z} \ddot{\varphi}_{r}-m_{s} e\left(\dot{v}_{y}+v_{x} w_{r}\right)+I_{x z} \dot{w}_{r}=m_{s} g e \sin \varphi-K_{\varphi} \varphi-C_{\varphi} \ddot{\varphi}
$$

Wheel rotation equation:

$$
I_{w} \dot{w}_{i j}=T_{m d i j}-F_{x i} R+\Delta M^{\prime}
$$
Where $\sum F_{x}$ and $\sum F_{y}$ are the longitudinal combined force and lateral force of the car; $\delta_{f}$ is the steering angle of the steering wheel; $v_{x}$ and $v_{y}$ is the longitudinal speed and lateral speed of the car; $m$ is the mass of the car; $m_{s}$ is the mass of the sprung; the $a$ and $b$ are the distance from the center of mass of the car to the front and rear axles; $h_{g}$ is the center of mass of the car; $e$ is the center of mass of the car to the center of the roll; $d$ is the wheelbase of the front and rear wheels; $I_{x}, I_{z}$, and $I_{x z}$ are the moment of inertia and inertia product of the sprung mass around the X-axis and Z-axis, respectively; $I_{w}$ is the moment of inertia of the wheel; $\varphi$ is the body roll angle; $\beta$ is the centric side angle; $w_{r}$ is the yaw rate; $K_{\varphi}$ and $C_{\varphi}$ are the equivalent roll stiffness and damping of the suspension respectively; $T_{m d i j}$ is the driving torque transmitted to the wheel by the motor; $w_{i j}$ is the speed of each wheel; $V_{m i j}$ is the longitudinal speed of each wheel; $\Delta M$ is the additional yaw moment of active intervention, which 
is generated by the driving wheel by adjusting the longitudinal driving force; $\Delta M^{\prime}$ is the torque transmitted to the wheel by the additional yaw moment.

\section{(2) Tire model}

Whether it is a traditional fuel car or an autonomous smart car studied in this paper, the tire model plays the vital role in the study of its shifting. Whether accelerating or braking, the force to maintain its shifting force comes from the adhesion of the tire to the ground (Vahidi et al. 2016).

Considering that the "magic formula" tire model has fewer parameters, the longitudinal force, lateral force and returning moment of the tire can be fully expressed by only one formula.

The physical meaning of each parameter is clear and can better simulate the tire characteristics of the tire under various working conditions (Vahidi \& Saberinia 2017).

Therefore, this paper selects the "magic formula" tire model for the simulation study of vehicle shift control (Zong et al. 2016).

The relationship between the tire force and the longitudinal slip $\mathrm{S}$ or the side yaw angle and the vertical load in the expression (6) by the "magic formula":

$$
Y(x)=D \sin \{C \arctan [B x-E(B x-\arctan (B x))]\}+S_{v}
$$

Where $Y$ is the longitudinal force or lateral force of the tire; $x$ is the longitudinal slip ratio or the side declination. $C$ is the curve trait factor, $\mathrm{D}$ is a peak factor, $B$ is the stiffness factor, and $E$ is the curvature factor. $S_{v}$ is vertical drift and their values are determined by wheel load.

\section{(3) Motor control model}

When the car is running, the vehicle controller sends a therapeutic output electromagnetic torque to the motor controller by receiving the target driving torque signal of the accelerator pedal to drive the wheels. Since the motor is directly connected to the wheel, assuming that the torque loss is not counted and the rotational efficiency is $100 \%$, the motor model is described as follows:

$$
\begin{aligned}
& T_{e i j}-T_{L i j}-r \cdot w_{i j}=J_{w i j} \dot{w}_{i j} \\
& T_{e i j}=K_{m} \cdot i_{a i j} \\
& E_{i j}-K_{e} \cdot w_{i j}-R \cdot i_{a i j}=L_{a} \cdot i_{a i j}
\end{aligned}
$$

Where $T_{e i j}$ is the electromagnetic torque; $T_{L i j}$ is the load torque; $J_{w i j}$ is the motor shaft and wheel moment of inertia; $w_{i j}$ is the motor speed; $K_{e}$ is the back electromotive force coefficient; $K_{m}$ is the torque coefficient; $i_{a i j}$ is the motor current; $R$ is the armature resistance. $L_{a}$ is the motor inductance; $E_{i j}$ is the input voltage; $r$ is the motor viscous friction coefficient.

In this paper, the motor torque is controlled by conventional PI ( $k_{p}$ is proportional and $k_{i}$ is integral) to generate the motor input voltage, namely:

$$
E_{i j}=k_{p}\left(T_{e d i j}-T_{e i j}\right)+k_{i} \cdot \int\left(T_{e d i j}-T_{e i j}\right) d t
$$

\subsubsection{Speed Control Strategy Based on Improved PID Control Algorithm}

\section{(1) Incremental PID control}

This solution uses incremental PID to enable unmanned smart cars to travel at the constant speed (Chenet al. 2016).

The calculation formula of the signal M2 highfrequency reference signal $\mathrm{T}$ in the speed control of the incremental PID is as shown in equation (11):

$$
\Delta u_{n}=u_{n}-u_{n-1}=k_{p}\left[\left(e_{n}-e_{n-1}\right)+\frac{1}{T_{1}} e_{n}+\frac{T_{d}}{T}\left(e_{n}-2 e_{n-1}+e_{n-2}\right)\right]
$$

Where $u_{n}$ is the current speed output increment; $u_{n-1}$ is the last speed output increment; $k_{p}$ is the proportional gain; $T$ is the sampling period; $T_{1}$ is the integration period; $T_{d}$ is the differential period; $e_{n}$ is the nth deviation; $e_{n-1}$ is the n- 1 th deviation.

\section{(2) Improve incremental PID control}

The idea of the improved incremental PID control is that the speed error $e_{n}$ means the given speed minus the feedback speed. When $e_{n}$ is greater than the set value $e_{k}$, the maximum value $u_{\max }$ is forcibly output; conversely, if the speed error $e_{n}$ is less than the set value $\left(-e_{k}\right)$, the minimum value $u_{\max }$ is forcibly output. The calculation formula is as shown in equation (12):

$$
u_{n}= \begin{cases}u_{\max } & e_{n}>e_{k} \\ u_{\min } & e_{n}<-e_{k}\end{cases}
$$

Where $e_{n}$ is the difference between the given speeds minus the feedback speed. 
In order to achieve the high-speed and stable driving of the smart car at the high speed when the road curvature does not change much, incremental PID control is used (Rahman et al. 2016).

When driving straight from the straight road into the corner, the smart car can quickly reverse the brakes, reduce the speed, and thus pass the curve well; when the car enters the straight, it can quickly increase the speed and drive at a high speed on the straight.

The speed control strategy we employ is improved incremental PID control. When the given speed and the feedback speed are not much different, the incremental PID control is adopted; when the given speed and the feedback speed are different, the incremental PID control is adopted.

The calculation formula is as shown in equation (13):

$$
u_{n}=\left\{\begin{array}{lc}
u_{\max } & e_{n}>e_{k} \\
u_{n-1}+k_{p}\left[\left(e_{n}-e_{n-1}\right)+k_{i} e_{n}+k_{d}\left(e_{n}-2 e_{n-1}+e_{n-2}\right)-e_{k} \leq e_{n} \leq e_{k}\right] \\
u_{\min } & e_{n}<-e_{k}
\end{array}\right.
$$

where $k_{d}$ is the differential coefficient.

\section{(3) Speed control cycle}

The speed measurement program is completed by the lidar high-speed data acquisition module, that is, every revolution $(0.17 \mathrm{~m})$ of the wheel, 20 interruptions will be generated.

During these 20 interruptions, 20 speed detections can be run.

If the average speed is $1.8 \mathrm{~m} / \mathrm{s}$, then the time for each input capture interrupt is $0.17 /(18 \times 20)=4.7 \mathrm{~ms}$, that is, the feedback speed is obtained every $4.7 \mathrm{~ms}$.

The speed control program refers to the closedloop control of the speed of the motor drive module at the given speed and feedback speed at regular intervals.

The feedback speed is read by the abovementioned lidar high-speed data acquisition module, and the given speed is obtained by query.

The speed control program is executed in the timer interrupt routine, and the timer interrupt is implemented by the modulo down counter.

Isochronous control means that the control program is executed once every certain time.

Isometric control means that the control program is executed once every certain distance. Since the control cycle is not controlled by the vehicle speed, isochronous control is superior to equidistant control (Gabbar \& Othman 2016).

In the first scheme, the self-made reflective infrared tube is used for speed measurement, and the price is cheap, but the control period is isochronous; the second scheme uses the rotary encoder to measure the speed, which is expensive, but the speed measurement accuracy is relatively high, and the control period is isochronous.

Our solution uses reflective infrared to measure the speed of the tube, the price is cheap, and the control period is isochronous.

The flow chart of motor speed control is shown in Fig. 5:

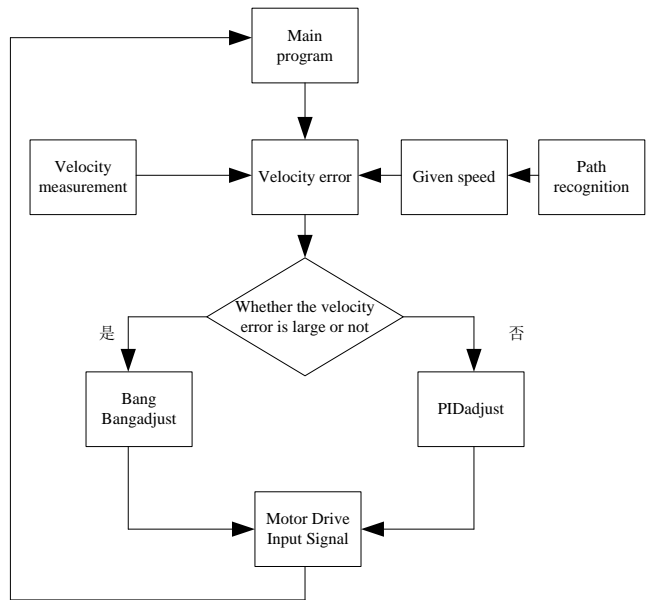

Figure 5: Flow chart of motor speed control

\section{Results}

\subsection{Effectiveness analysis}

\section{(1) Lane change curve test}

The vehicle lane change curve test is usually used to test the vehicle's handling performance. It can test the running performance of the vehicle and the quick response and control ability to changes in speed and curvature.

The test sets the vehicle lane change test curve as shown in Fig. 6:

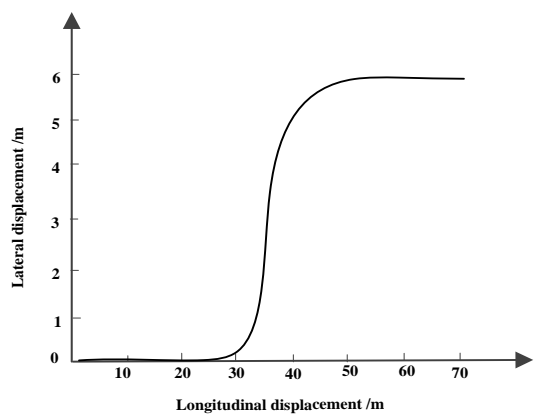

Figure 6: Test curve of vehicle lane change 
The trajectory simulation results of the system after the lane change control of the unmanned vehicle in this paper are shown in Fig. 7:

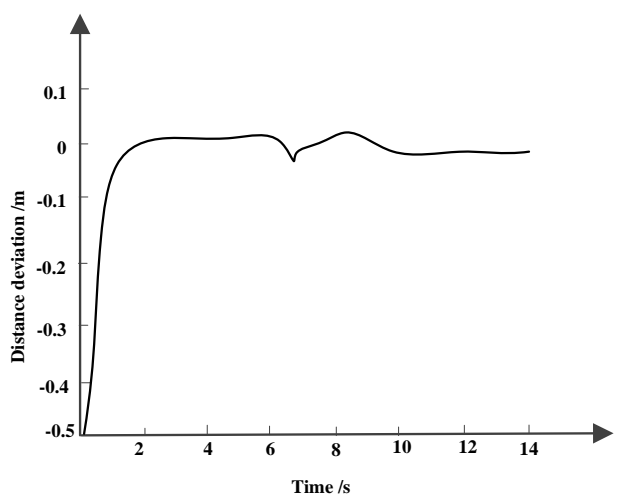

(a) Result of distance deviation

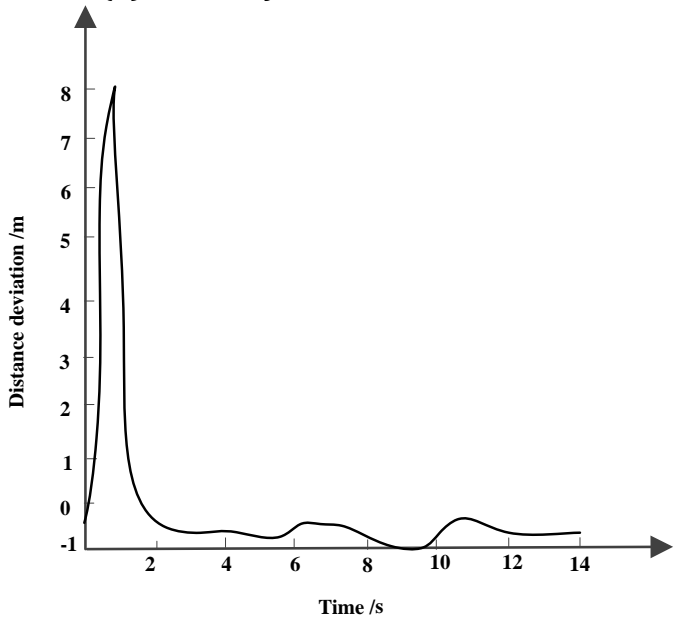

(b) Result of azimuth deviation

Figure 7: Simulation results of lane change curve

It can be seen from Fig. 7 that when the vehicle is changing lanes, the system overcomes the influence of the initial deviation and has the faster convergence speed.

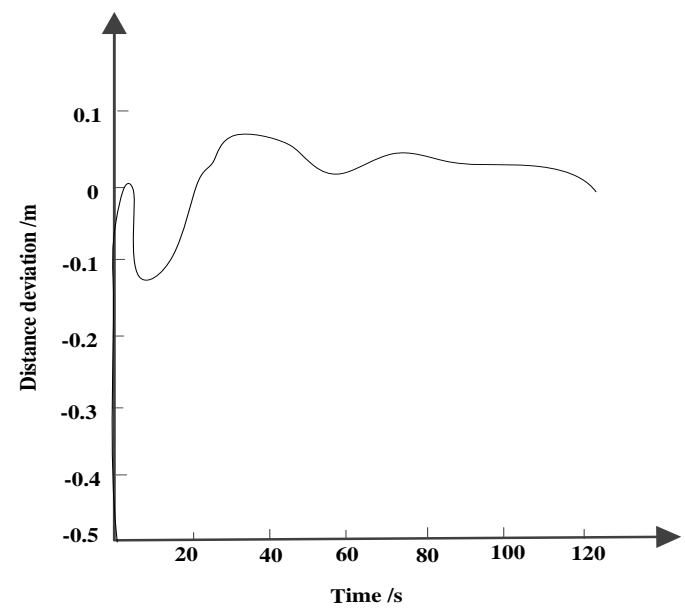

(a) Result of distance deviation
After the shifting lane change, the distance deviation of the vehicle after running is stable is in the range of $-0.1-0.1 \mathrm{~m}$, and the azimuth deviation is in the range of $-1^{\circ}-1^{\circ}$. The error of the curve test is within the reasonable range.

This indicates that the system can accurately and stably control the running speed of the vehicle when it is performing the linear and curved shifting operation, and has the quick response capability to the curvature change.

\section{(2) 8-shaped curve test}

The 8-shaped curve is not common in everyday driving, but it provides an intuitive feel for vehicle speed control, where the curvature at the two arc joints is discontinuous.

Therefore, it can also be used to verify the stability of the intelligent shift control system of the unmanned vehicle.

The test curve of the " 8 " shape set by the test is shown in Fig. 8:

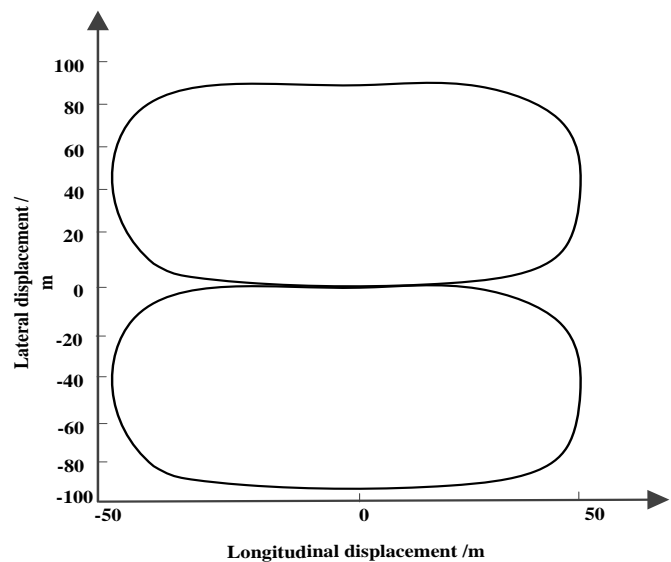

Figure 8: Eight-shaped test curve

The simulation results of the 8-shaped curve shift control of the system in this paper are shown in Fig. 9:

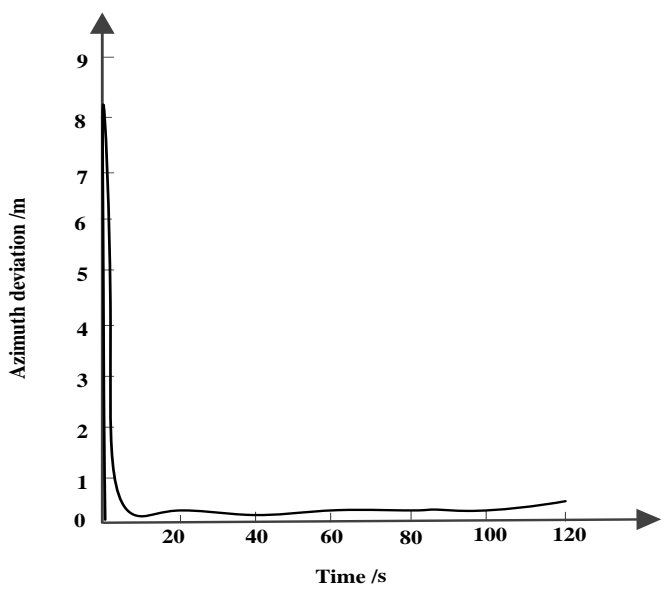

(b) Result of azimuth deviation

Figure 9: Simulation results of eight-shaped curves test 
It can be seen from Fig. 9 that the system overcomes the influence of the initial lateral deviation when the vehicle shifts lanes on the figureeight curved road. It has a faster convergence speed when controlling the vehicle's variable speed operation. Although the distance deviation of the vehicle after running is stable, it has the certain steady-state error, but it is in the range of $-0.1-0.1 \mathrm{~m}$, and the variation of the distance deviation curve is softer. The steady-state error is getting smaller and smaller, and the azimuth deviation is controlled within the range of $-1^{\circ}$ to $1^{\circ}$. The error of the curve shifting lane test is within a reasonable range, which indicates that the system can quickly and accurately perform intelligent shift control according to the predetermined curve, and can ensure the smoothness during operation.

\subsection{Performance Analysis}

The system of this paper, the unmanned vehicle system based on extended hybrid Petri net, and the intelligent car control system based on single-chip microcomputer are used to control the speed of the unmanned vehicle target speed curve.

The control performance of the three systems is compared and analyzed from different performance indicators, and the relatively intelligent and efficient shift control system is evaluated.

Fig. 10 depicts the control effects of the three systems on the intelligent shifting of unmanned vehicles without damping:

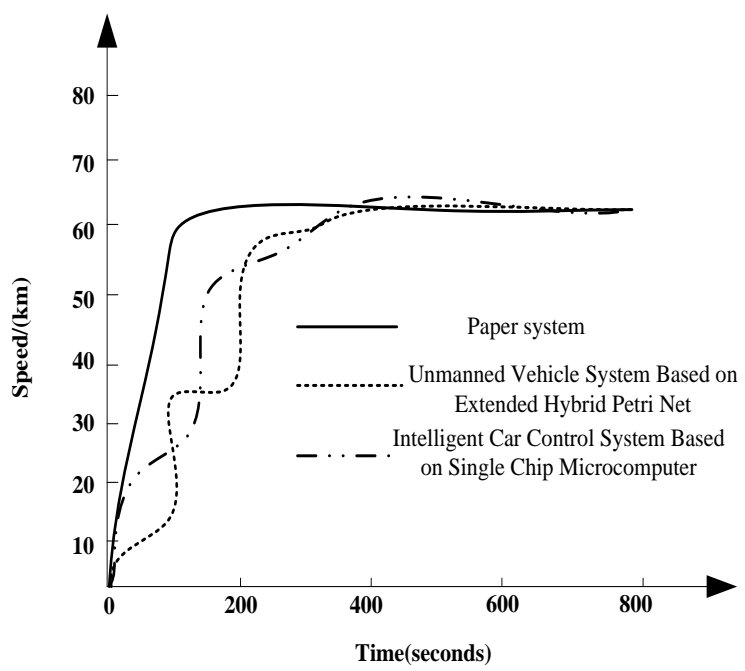

Figure 10: Velocity Control Effect of Three Systems without Damping

Analysis of Fig. 10 shows that after the system controls the unmanned vehicle for 150 seconds, the speed reaches $60 \mathrm{~km}$, and the vehicle speed curve quickly converges and reaches a steady state. Under the control of the remaining two systems, the driving speed curve gradually converges after 300 seconds.
This shows that the system has better convergence when controlling the shift of the unmanned vehicle, and can quickly reach the target speed.

Fig. 11 depicts the control effects of the three systems on the intelligent shift of the unmanned vehicle under the premise of damping:

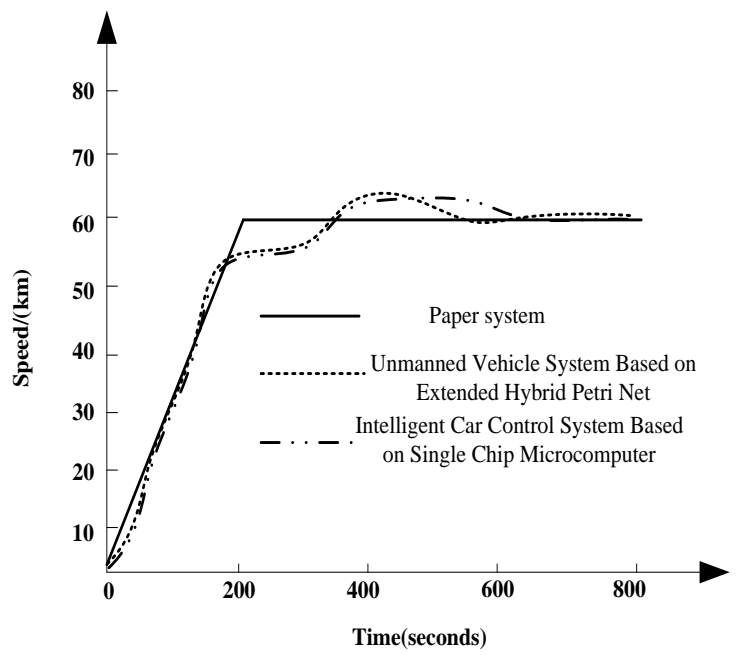

Figure 11: The control effect of three systems on intelligent transmission of unmanned vehicle with damping 
Analysis of Fig. 11 shows that after 200 seconds of shift control of the unmanned vehicle in this system, the vehicle speed curve quickly converges and reaches the steady state.

The unmanned vehicle system based on the extended hybrid Petri net and the intelligent car control system based on single-chip microcomputer have poor convergence of the shift control curve of the unmanned vehicle, resulting in more unmanned vehicle speed fluctuations and tend to be stable after 600 seconds.

The variable speed control of this system is the best.

Table 1 describes the control time-consuming comparison of the three system shifts with a total distance of $10 \mathrm{~km}$ under different situation settings:

Table 1 Time-consuming results of variable speed control for 3 systems

\begin{tabular}{|c|c|c|c|c|c|c|c|c|c|c|c|c|}
\hline \multirow{2}{*}{$\begin{array}{l}\text { Number of } \\
\text { experiments }\end{array}$} & \multicolumn{4}{|c|}{ Paper system } & \multicolumn{4}{|c|}{$\begin{array}{l}\text { Unmanned Vehicle System Based on } \\
\text { Extended Hybrid Petri Net }\end{array}$} & \multicolumn{4}{|c|}{$\begin{array}{l}\text { Intelligent Car Control System } \\
\text { Based on Single Chip } \\
\text { Microcomputer }\end{array}$} \\
\hline & $\begin{array}{c}\text { Static- } \\
\text { Start- } \\
\text { Accelerate }\end{array}$ & $\begin{array}{l}\text { Static- } \\
\text { Start- } \\
\text { Decelera } \\
\text { tion }\end{array}$ & $\begin{array}{c}\text { Accelerati } \\
\text { on- } \\
\text { parking }\end{array}$ & $\begin{array}{c}\text { Decelerat } \\
\text { ion- } \\
\text { parking }\end{array}$ & $\begin{array}{l}\text { Static- } \\
\text { Start- } \\
\text { Accelerate }\end{array}$ & $\begin{array}{l}\text { Static- } \\
\text { Start- } \\
\text { Decele } \\
\text { ration }\end{array}$ & $\begin{array}{c}\text { Accelera } \\
\text { tion- } \\
\text { parking }\end{array}$ & $\begin{array}{c}\text { Decelera } \\
\text { tion } \\
\text { parking }\end{array}$ & $\begin{array}{l}\text { Static- } \\
\text { Start- } \\
\text { Accele } \\
\text { rate }\end{array}$ & $\begin{array}{l}\text { Static- } \\
\text { Start- } \\
\text { Decele } \\
\text { ration }\end{array}$ & $\begin{array}{c}\text { Accelerat } \\
\text { ion- } \\
\text { parking }\end{array}$ & $\begin{array}{c}\text { Decelerat } \\
\text { ion- } \\
\text { parking }\end{array}$ \\
\hline 1 & 501 & 503 & 498 & 499 & 699 & 698 & 614 & 618 & 802 & 804 & 814 & 818 \\
\hline 2 & 502 & 502 & 499 & 496 & 699 & 698 & 614 & 619 & 803 & 804 & 814 & 819 \\
\hline 3 & 501 & 503 & 499 & 494 & 698 & 698 & 616 & 619 & 804 & 804 & 816 & 819 \\
\hline 4 & 501 & 503 & 499 & 494 & 698 & 698 & 617 & 619 & 804 & 804 & 817 & 819 \\
\hline 5 & 501 & 503 & 495 & 494 & 698 & 698 & 616 & 619 & 804 & 803 & 816 & 819 \\
\hline 6 & 501 & 501 & 495 & 494 & 698 & 698 & 616 & 619 & 804 & 803 & 816 & 819 \\
\hline 7 & 501 & 503 & 494 & 494 & 698 & 698 & 616 & 620 & 804 & 803 & 816 & 820 \\
\hline 8 & 501 & 502 & 495 & 495 & 698 & 698 & 616 & 619 & 804 & 803 & 816 & 819 \\
\hline 9 & 501 & 502 & 494 & 495 & 698 & 698 & 616 & 620 & 804 & 803 & 816 & 820 \\
\hline 10 & 501 & 502 & 495 & 495 & 696 & 698 & 616 & 620 & 804 & 803 & 816 & 820 \\
\hline
\end{tabular}

Analysis of Table 1 data shows that when the static-start-acceleration state is required, the control time of this system is 502s maximum; when staticstart-deceleration is required, the control time of this system is 503s. When acceleration-stop is required, the control time of this system is $499 \mathrm{~s}$ maximum; when deceleration-stop is required, the control time of this system is $499 \mathrm{~s}$.
The control time of the unmanned vehicle system based on the extended hybrid Petri net and the intelligent car control system based on the singlechip microcomputer is greater than that of the system under the four requirements.

This shows that the control of the system in this paper is short-lived. 


\section{Discussion}

At present, the domestic unmanned driving technology has been continuously developed and made great progress. Driverless cars have gained public recognition, but the need to achieve universalization of driverless cars still requires a long way to go. The key technical level is not high, the parts are not localized seriously, the policies and regulations need to be improved, and so on. This article discusses the following issues and difficulties in the future of driverless cars:

\section{(1) Technical issues.}

At present, the exploration of domestic unmanned technology is still based on the technology that has emerged abroad, and it is mainly divided into two patterns. One is that automotive companies mainly use the US Tesla technology as a model; the other is based on the Google technology route as a standard. Precise positioning and navigation is the most important part of unmanned driving. Only the precise positioning and navigation can ensure the safety and reliability of driverless driving. High-precision GPS is subject to foreign restrictions and cannot be applied to civilian vehicles. However, ordinary civilian GPS sensitivity is flawed and cannot be accurately positioned. Although the Beidou navigation system independently developed by China has been put into use, it still has a long way to go to catch up with GPS.

At present, it is widely used in cooperation with electronic map surveying and mapping enterprises to obtain the relative accuracy of positioning. Invehicle sensors and high-precision laser radars are used as the eyes of automobiles. There is no guarantee in China that the accuracy requirements are still subject to people. How to realize the localization of vehicle control technology is not only the inevitable problem of unmanned driving, but also the problem that China's automobile industry must solve in the world.

\section{(2)Policies and regulations.}

Although developed countries such as the United States and Japan have encouraged the rapid development of driverless technology, they have also imposed clear restrictions on the driving of unmanned vehicles. How to achieve unmanned driving in the true sense is the problem we must face. If the driverless car wants to travel legally, it must first solve the problems of policies and regulations. It is inevitable that an accident will occur for a driverless car for some reason.

How to divide the responsibility of the accident, and how to make a fair ruling, these are all issues that need to be discussed and verified in depth. At present, there are no countries that have formulated comprehensive policies and regulations for driverless cars. To truly realize the popularization of driverless cars, this is the problem that must be solved and requires extra care.

\section{(3)Difficulties.}

In some special circumstances, people are difficult to survive, and driverless can overcome these problems. However, it also needs to address the effects of extreme environments such as extreme cold and complex road conditions. This is also the same difficulty for all future development of driverless. On the highway, unmanned car owners can strictly follow the road safety signs and vehicle identification information, which can largely solve the danger caused by fatigue and other factors. In the urban road conditions, due to the complicated road conditions and the mobility of personnel, it is necessary to pay attention to the road information when driving the vehicle, which has higher requirements for the sensing and artificial intelligence control algorithms. Unmanned driving in urban environments is the greater challenge for unmanned technology. How to improve driving maneuverability and safety will be the difficult point for unmanned driving in the future.

\section{Conclusions}

The small unmanned vehicle intelligent shifting system based on PID control algorithm is designed in this paper. After the environmental information around the vehicle is collected by the laser radar high-speed data acquisition module, it is transmitted to the decision-making planning module. According to the detailed information, the corresponding operation instructions are given to the driverless smart car. Operational commands are transmitted to the motor drive module to control intelligent shifting. Therefore, the vehicle dynamics model is constructed, and the speed control strategy based on the improved PID control algorithm is used to complete the intelligent shift control of the unmanned vehicle. Applying the system to the simulation experiment, the system can effectively control the unmanned vehicle to change the lane according to the actual road conditions in different environments.

Compared with the comparison system, the system has better convergence and can reach the target speed quickly. And its control takes the shortest time and has a certain use value.

The car of the future is not only a means of transportation, but also the new generation of Internet terminals. Driverless cars integrate perception, decision making, control and feedback into one system to ensure that the car is out of the driver and that its driving maneuverability and safety are guaranteed. The emergence of driverless will fundamentally change the control mode of traditional cars, which has greater security for the safety and traffic efficiency of the transportation system. With the continuous development of big data, Internet of Things, and cloud computing, the performance of driverless cars will be more perfect. 
We believe that in the near future, driverless cars will be on the land of China.

\section{Reference}

[1] Ali, A.A. 2017. Symbiotic Organisms Search Algorithm for Automatic Generation Control of Interconnected Power Systems Including Wind Farms. Iet Generation Transmission \& Distribution 11(7):1692-1700.

[2] Brock, P.M., Fornace, K.M., Parmiter, M. 2016. Plasmodium Knowlesi Transmission: Integrating Quantitative Approaches from Epidemiology and Ecology to Understand Malaria as a Zoonosis. Parasitology143 (4):389400.

[3] Chen, F., Wen, L., Zhang, K. 2016. A Novel Nonlinear Resilient Control for a Quadrotor UAV Via Backstepping Control and Nonlinear Disturbance Observer. Nonlinear Dynamics 85(2):1281-1295.

[4] Chen, M., Mozaffari, M., Saad, W. 2017. Caching in the Sky: Proactive Deployment of CacheEnabled Unmanned Aerial Vehicles for Optimized Quality-of-Experience. IEEE Journal on Selected Areas in Communications 35(5):1046-1061.

[5] Du, C.Q.,Pan, Z.Q., Zhao, Y.F.2016.Research on On-Board Charging System for Electric Vehicle.Chinese Journal of Power Sources 40(6):1277-1279.

[6] Fillafer, C., Schneider, M.F. 2016. On the Excitation of Action Potentials by Protons and Its Potential Implications for Cholinergic Transmission. Protoplasma 253(2):357-365.

[7] Gabbar, H.A., Othman, A.M. 2016. Performance Optimisation for Novel Green Plug-Energy Economizer in Micro-Grids Based on Recent Heuristic Algorithm. Iet Generation Transmission \& Distribution 10(3):678-687.

[8] Gao, Z.R.,Zhou, F., Zhao, Q.J. 2018.Research on Dynamic Detection Technology of Optoelectronic Slip Rings.Journal of China Academy of Electronics and Information Technology 13(2):64-70.

[9] Hasanien, H.M.2018. Whale Optimisation Algorithm for Automatic Generation Control of Interconnected Modern Power Systems Including Renewable Energy Sources. Iet Generation Transmission \& Distribution 12(3):607-614.

[10] Jin, L., Han, Y. 2017. Optimal Resource Allocation for Packet Delay Minimization in Multi-Layer UAV Networks. IEEE Communications Letters 21(3):580-583.

[11] Luo, L.M.,Wang, M.X., Guo, Y.H.2018.Design of Intelligent Car Control System Based on MCU.Instrument Technique and Sensor 420(1):126-129.
[12] Lv, H.,Liu, C.Z. 2016. Design on Balancing Circuits for LiFePO4 Battery Stacks in Electric Vehicles.Journal of Power Supply 14(1):95-101.

[13] Rahman, A., Saikia, L.C. Sinha, N. 2016. Automatic Generation Control of an Unequal Four-Area Thermal System Using Biogeography-Based Optimised 3DOF-PID Controller. Iet Generation Transmission \& Distribution 10(16):4118-4129.

[14] Rahman, A., Saikia, L.C., Sinha, N. 2016. Maiden Application of Hybrid Pattern SearchBiogeography Based Optimisation Technique in Automatic Generation Control of a Multi-Area System Incorporating Interline Power Flow Controller. Iet Generation Transmission \& Distribution 10(7):1654-1662.

[15] Ren, Z.L., He, J.L., Qin, L.Q. 2016.A Study of Meshing Quality and Fatigue Properties of Auto Transmission. Computer Simulation 33(8):125130.

[16] Song, X.J., Zhang, G.Q. 2017. Modeling and Analysis of CPS Unmanned Vehicle Systems Based on Extended Hybrid Petri Net. Computer Science 44(7):21-24.

[17] Vahidi, V., Saberinia, E.2017. OFDM for Payload Communications of UAS: Channel Estimation and ICI Mitigation. Iet Communications 11(15):2350-2356.

[18] Vahidi, V., Yazdanpanah, A.P., Saberinia, E. 2016. Channel Estimation, Equalisation, and Evaluation for High-Mobility Airborne Hyperspectral Data Transmission. Iet Communications 10(18):2656-2662.

[19] Wang, S., Gasparri, A., Krishnamachari, B. 2017. Robotic Message Ferrying for Wireless Networks Using Coarse-Grained Backpressure Control. IEEE Transactions on Mobile Computing 16(2):498-510.

[20] Wei, Z., Wu, H., Huang, S. 2017. Scaling Laws of Unmanned Aerial Vehicle Network with Mobility Pattern Information. IEEE Communications Letters 21(6):1389-1392.

[21] Xie, H., Lynch, A.F. 2016. State TransformationBased Dynamic Visual Servoing for an Unmanned Aerial Vehicle. International Journal of Control 89(5):892-908.

[22] Xing, F., Wu, A., Shang, Y. 2016. A Novel Sliding Mode Controller for Small-Scale Unmanned Helicopters with Mismatched Disturbance. Nonlinear Dynamics 83(1-2):1053-1068.

[23] Yu, S.L.,Xiao, L.L., Jian, M.Z. 2016.Intelligent Vehicle Speed Control Based on Fuzzy PID and Algorithms.Automation \& Instrumentation (2):76-77.

[24] Zong, X., Dong, W., Han, Y.2016. Development of $35 \mathrm{kV}$ 2000A CD HTS Cable Demonstration Project. IEEE Transactions on Applied Superconductivity 26(7):1-4. 